\title{
Postpartum family planning: current evidence on successful interventions
}

\author{
This article was published in the following Dove Press journal: \\ Open Access Journal of Contraception \\ II April 2016 \\ Number of times this article has been viewed
}

\section{Cassandra Blazer Ndola Prata \\ Bixby Center for Population, Health, and Sustainability, School of Public Health, University of California, Berkeley, CA, USA}

\begin{abstract}
We reviewed existing evidence of the efficacy of postpartum family planning interventions targeting women in the 12 months postpartum period in low- and middle-income countries. We searched for studies from January 1, 2004 to September 19, 2015, using the US Preventive Services Task Force recommendations to assess evidence quality. Our search resulted in 26 studies: 11 based in sub-Saharan Africa, six in the Middle East and North Africa, and nine in Asia. Twenty of the included studies assessed health facility-based interventions. Three were focused on community interventions, two had community and facility components, and one was a workplace program. Overall quality of the evidence was moderate, including evidence for counseling interventions. Male partner involvement, integration with other service delivery platforms, such as prevention of mother-to-child transmission of HIV and immunization, and innovative product delivery programs may increase knowledge and use during the postpartum period. Community-based and workplace strategies need a much stronger base of evidence to prompt recommendations.
\end{abstract}

Keywords: postpartum period, family planning, birth spacing, interventions, systematic review, contraception, less developed countries

\section{Introduction}

Evidence shows that family planning (FP) is a cost-effective public health intervention with the potential to reduce both maternal and child mortality. ${ }^{1}$ However, around 222 million women have an unmet need for FP, with the majority of these women living in low- and middle-income countries. ${ }^{2}$ There were 213 million pregnancies in 2012, most of which ended in birth. ${ }^{3}$ This number will certainly increase as the global population continues to grow, and the large proportion of youth enter their childbearing years. ${ }^{4}$ Regardless of whether the growing number of births are intended or unintended, they indicate an immense opportunity to reach postpartum women with FP for spacing subsequent pregnancies. Citing the prospective definition of unmet need for FP, which uses a postpartum woman's fertility preferences looking forward at the time of the survey, as many as 50\%-90\% of women from 17 low- and middle-income countries (LMICs) report an unmet need for postpartum family planning (PPFP). ${ }^{5}$

Women frequently return to fertility and sex before initiating contraception after delivery, and do not necessarily understand the risk of pregnancy before the return of menses. For example, Borda et al, ${ }^{5}$ report on Demographic and Health Survey (DHS) data showing that in Bangladesh, 33\% of women resumed sexual activity within 3 months postpartum, but only $7.2 \%$ were using contraception. In Rwanda, these 
proportions are $73.6 \%$ and $1.7 \%$, respectively. In all 17 countries analyzed, women were more likely to use contraception after menses returned than before. FP is critical for saving the lives of women and children in the developing world. ${ }^{6}$ The World Health Organization (WHO $)^{7}$ recommends PPFP as a critical component of health care that has the potential to meet women's desire for contraception and save millions of maternal and infant lives in low- and middle-income countries.

This review aims to answer the research question: what recent interventions in LMIC have led to improvements in postpartum FP outcomes? The purpose of this review is to add to the existing body of evidence by casting a wide net in an attempt to capture the recent intervention strategies that present the most promise for decreasing the unmet need for contraception among postpartum women living in low- and middle-income countries (those defined as "developing" by the World Bank). The postpartum period is defined here as the 12-month period after delivery. We will assess the effectiveness of PPFP interventions on clients' contraceptive knowledge, intention to use PPFP, and PPFP use. We capture both peer-reviewed and programmatic literature, reviewing only strategies tested in LMICs. We present a synthesis of the most recent programmatic and peer-reviewed literature, specific to interventions that are facility-based, communitybased, and integrated strategies aiming to reach postpartum women.

\section{Background Efforts in PPFP}

Several programs have aimed to improve rates of PPFP among women in low- and middle-income countries (including Access to Clinical and Community Maternal, Neonatal, and Women's Health Services - Family Planning Initiative (ACCESS-FP), CATALYST Consortium, Frontiers in Reproductive Health Program (FRONTIERS), Knowledge for Health (K4Health), Maternal and Child Health Integrated Program (MCHIP), Basic Support for Institutionalizing Child Survival (BASICS), and more). Studies have assessed intervention strategies to increase the use of contraception in the immediate and extended postpartum periods. Existing evidence to date assessing interventions to increase postpartum contraception includes seven reviews:

- Koblinsky ${ }^{8}$ reviewed the evidence for community-based postpartum care, including integrated maternal and newborn care and FP. The author reviewed studies from 1970 to 2004 that included a community-based intervention aimed to improve postpartum care, the size of the target community, and a comparison group. Studies that described barriers to and/or quality of community-based postpartum care were also included. Koblinsky (2005) outlined three program models with their advantages and disadvantages: home visits by skilled clinicians are feasible but resource-intensive, home visits by community workers are feasible and potentially cost-effective, and home visits with a referral mechanism back to the health facility are feasible but not highly effective. She recommends policy, programmatic, and future research considerations, including how to deliver postpartum care in the community, and who is best positioned to provide such care. The review presented important implications for programs. However, it did not include an assessment of the quality of the evidence, and an update reviewing the past 10 years of programs since this review was conducted is in order.

- Vernon ${ }^{9}$ described programmatic lessons learned and key strategies for reaching postpartum women with FP messages, products, and services. Studies included program data, operations research using small samples, and nonexperimental design. Vernon notes several practices to reduce unmet need in the postpartum period, including antenatal counseling on FP, male involvement, integration of FP with postnatal care in health facilities, promotion of lactational amenorrhea method (LAM) and postpartum intrauterine device (IUD) placement with appropriate patient consent, practices to improve the postnatal care outpatient visit, and community-based care. Although also without an assessment of the quality of the evidence, the review provides insights from programmatic data that would not be included in systematic reviews.

- Yeakey et $\mathrm{al}^{10}$ reviewed the effects of contraceptive use on neonatal and infant mortality. Articles from 1980 to 2008 with outcomes related to contraceptive use and birth intervals were included. Although a few studies included in this review had mixed results, there is evidence that use of contraceptives protects against short birth intervals, a pathway to adverse effects on neonatal and birth outcomes. The review demonstrated what has worked and what has not in increasing birth spacing.

- Lopez et $\mathrm{al}^{11}$ assessed the evidence from randomized controlled trials in any country on the effect of contraceptive education on postpartum contraceptive use. Findings revealed that half of the included studies resulted in increased postpartum contraception use and lower birth rates, with an overall moderate quality of evidence according to Cochrane review criteria. This review does 
not include case-control or cohort studies, and thus omits much of the evidence on FP that is currently available. By including less rigorous research designs, this review builds upon this important work.

- Arrowsmith et $\mathrm{l}^{12}$ assessed interventions to increase the use of copper IUDs. Randomized controlled trials and controlled before and after studies from any country that measured use of copper IUD between 1990 and 2011 were included. Antenatal contraceptive counseling for postpartum contraceptive use and postdelivery contraceptive counseling with a leaflet prior to hospital discharge significantly increased the number of women who accepted the IUD. Postnatal home visits did not significantly improve IUD uptake.

- Sonalkar et a $1^{13}$ looked at the efficacy of various PPFP strategies on increasing contraception in the year postpartum, and assessed the quality of the evidence. The authors reviewed randomized controlled trials, and case-control, cross-sectional, and cohort studies globally through March 2013. The primary outcome of interest was interpregnancy interval, and the secondary outcome was contraceptive use. Although they conclude there is evidence that program interventions may extend birth intervals and increase contraceptive use, most of the highest quality studies were conducted in high-income countries. The authors call for increased resources for high quality investigation of programs and a platform for in-depth description and discussion of promising programs and evaluation results.

- Cleland et al ${ }^{14}$ review programmatic efforts to increase PPFP in low- and middle-income countries. They identified 35 interventions not limited by year of publication for inclusion, and classify each study based on the timing and delivery type of the intervention, including antenatal, postnatal, combined, and interventions integrated with other services. Their excellent discussion contextualizes the studies within each of four common strategies: immediate update of contraception postpartum, LAM promotion with transition to a modern contraceptive method at 6 months, delaying contraceptive uptake until 6 weeks postpartum, or delaying contraception until return to menses. Our review offers a parallel insight to this work. Our results are reported by outcome rather than by intervention to assist program and policy planners in achieving their desired results. Our review identified eleven studies not included in the Cleland et al review, possibly due to the fact that we included research that aimed to improve knowledge outcomes, while Cleland et al focused on contraceptive use, unmet need, continuation, length of birth interval, and repeat pregnancy or abortion rates.

In short, previous reviews have done an important work of summarizing PPFP interventions. However, many papers focused on studies from high-income countries, restricted their analysis to studies with strong methodological rigor, or simply need to be updated. Finally, reviews by Sonalkar et $\mathrm{al}^{13}$ and Cleland et al ${ }^{14}$ identify more current programs to add to the knowledge base; however, this review identified eleven studies not incorporated into these more recent reviews. Despite these efforts and decades of evidence, effective interventions for decreasing unmet need in the postpartum period in low- and middle-income countries remain unclear. A review of current, promising programs in low- and middleincome countries might give programs the broadest range of strategy options to adapt and test in their contexts.

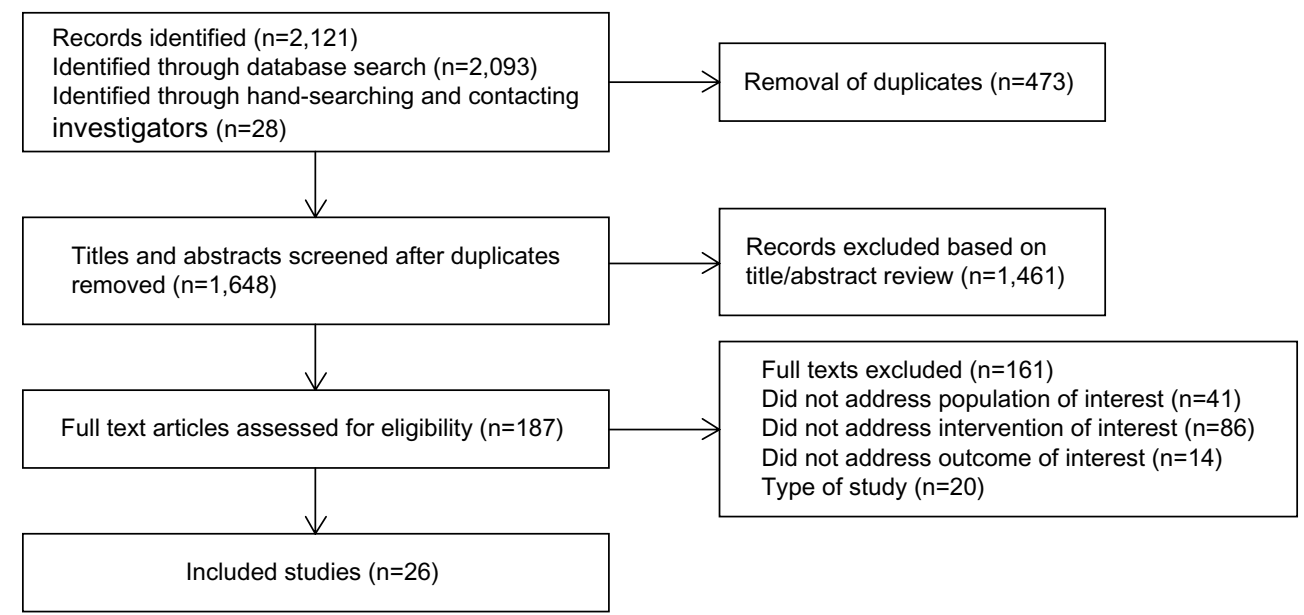

Figure I Flowchart of study search and selection process. 
Table I Inclusion and exclusion criteria

\begin{tabular}{|c|c|c|}
\hline $\begin{array}{l}\text { PICO } \\
\text { hierarchy }\end{array}$ & Inclusion criteria & Exclusion criteria \\
\hline Population & $\begin{array}{l}\text { Low- and middle-income countries } \\
\text { Women } \\
\text { Intervening prior to } 12 \text { months } \\
\text { postpartum }\end{array}$ & $\begin{array}{l}\text { Developed countries } \\
\text { Intervening with } \\
\text { women who are } \\
\text { not pregnant or in } \\
\text { the } 12 \text { months after } \\
\text { delivery }\end{array}$ \\
\hline Intervention & $\begin{array}{l}\text { Interventions targeting increasing } \\
\text { family planning outcomes during } \\
\text { the } 12 \text { months postpartum } \\
\text { Community- or facility-based }\end{array}$ & $\begin{array}{l}\text { Secondary data } \\
\text { analysis }\end{array}$ \\
\hline Comparison & $\begin{array}{l}\text { Comparison group necessary for } \\
\text { inclusion }\end{array}$ & $\begin{array}{l}\text { No comparison } \\
\text { group }\end{array}$ \\
\hline Outcomes & $\begin{array}{l}\text { Study must measure one or } \\
\text { more postpartum family planning } \\
\text { outcomes, including: I) knowledge } \\
\text { of postpartum family planning } \\
\text { among clients, 2) postpartum } \\
\text { family planning use, 3) use by } \\
\text { method type, 4) intention to use, } \\
\text { and 5) occurrence of pregnancy }\end{array}$ & $\begin{array}{l}\text { Study did not } \\
\text { measure postpartum } \\
\text { family planning } \\
\text { outcomes }\end{array}$ \\
\hline $\begin{array}{l}\text { Types of } \\
\text { studies }\end{array}$ & $\begin{array}{l}\text { Randomized controlled trials, } \\
\text { retrospective and prospective } \\
\text { cohort studies, controlled } \\
\text { pre-post intervention studies, } \\
\text { interrupted time series, case- } \\
\text { control studies, randomized and } \\
\text { nonrandomized, quantitative, } \\
\text { literature reviews, and } \\
\text { meta-analysis }\end{array}$ & $\begin{array}{l}\text { Qualitative studies } \\
\text { Descriptive studies } \\
\text { without outcome } \\
\text { measurement }\end{array}$ \\
\hline
\end{tabular}

Note: We excluded studies utilizing secondary data as the basis for analysis.

Abbreviation: PICO, population, intervention, comparison, outcome.

\section{Methods}

The identification, screening, eligibility, and review of studies followed Cochrane's PRISMA system ${ }^{15}$ (Figure 1). Both authors screened abstracts followed by full texts, excluding studies according to the PICO system ${ }^{16}$ (Table 1).

\section{Inclusion criteria}

\section{Population}

Studies were included if the intervention targeted women in low- and middle-income countries within 1 year postpartum. Intervention sites included facility and community settings. Strategies were delivered to women and men in the antenatal period, during labor and delivery, and the postpartum period. To be included, the study had to collect data related to FP during the woman's postpartum period.

\section{Intervention}

The intervention had to target PPFP and could be both supply and demand side interventions.

\section{Comparison}

We only included studies with some type of comparison group to demonstrate effectiveness. This included before and after studies with or without a nonintervention comparison group, case-control studies, cluster trials, and randomized controlled trials.

\section{Outcomes}

The studies included in this review had to use quantitative analysis, and report on one or more of the following outcomes: 1) knowledge of FP among clients ${ }^{1}$; 2) PPFP use; 3) PPFP use by method type, 4) intention to use PPFP; and 5) occurrence of pregnancy. The outcome knowledge of postpartum family planning included information about contraceptive methods, healthy spacing messages, breastfeeding as contraception, condoms as dual protection, and contraceptive methods for women living with HIV. However, none of the studies assessed changes in knowledge about fertility or understanding of pregnancy risk before return to menses, which may be a contributing factor to postpartum family planning use. For those studies that provided the data to compute statistical tests of significance but did not present $P$-values or the tests themselves, the authors conducted test for significance between groups using Stata 13 (StataCorp 2013. Stata Statistical Software: Release 13, StataCorp LP, College Station, TX, USA).

\section{Search methods}

We searched for eligible studies in English, Spanish, Italian, Portuguese, and French from January 1, 2004 to September 19, 2015 in PubMed, the Cochrane Central Register of Controlled Trials, Popline, and Web of Science using the following search terms and their iterations: postpartum, after delivery, postnatal, fertility regulation, family planning, contraception, birth spacing, child spacing, birth interval, pregnancy interval, interpregnancy interval, interpregnancy intervals. We searched for all original studies, project reports, conference abstracts, reviews, and systematic reviews. We hand-searched references of all full texts reviewed. We contacted investigators to obtain additional information as needed.

\section{Study selection and analysis}

Two authors reviewed all titles and abstracts extracted from the database search. Both authors then reviewed all full texts that were not excluded during title and abstract review, and made further exclusions. Discrepancies were resolved through discussion. Data extraction was performed for 
Table 2 US preventive task force hierarchy of research design

Type I Evidence obtained from at least one randomized controlled trial

Type II-I Evidence obtained from well-designed controlled trials without randomization

Type II-2 Evidence obtained from a well-designed cohort or case-control analytic study, preferably from more than one center or research group

Type II-3 Evidence obtained from multiple time series with or without the intervention (dramatic results from uncontrolled experiments could also be regarded as this type of evidence)

Type III Opinions of respected authorities, based on clinical experience, descriptive studies, and case reports or reports of expert committees

included studies, including intervention description, study description, results, and assessment of study bias.

We assessed risk of bias according to the domains in the Newcastle-Ottawa Scale ${ }^{17}$ for nonrandomized studies and the Cochrane Handbook ${ }^{18}$ for randomized controlled trials. These domains included: study design; selection, assignment, and comparability of comparison and control groups; attrition; spillover and contamination; quality of intervention description and implementation; representativeness of the study groups; and sample size. We used the US Preventive Services Task Force recommendations to assess the quality of the study design ${ }^{19}$ (Table 2). Taken together, the US Preventive Services Task Force classification and risk of bias assessment were used to identify the quality of the evidence presented in each included study.

We aggregated studies by outcomes assessed. For each outcome, we described the studies that measured that indicator by type of intervention. We then assessed the quality of the evidence for each outcome individually, concluding with an overall discussion of the quality of the evidence for PPFP interventions.

\section{Results}

Our database search resulted in 2,093 citations. An additional 28 references were located through hand-searching reference lists of full texts and communication with selected investigators. After 473 citations were removed because of duplication, two authors reviewed 1,648 titles and abstracts. We assessed the eligibility of 187 full texts. Twenty-six studies met the inclusion criteria for this review (see Figure 1).

Table 3 presents the reviewed studies, including intervention descriptions, the quality of the evidence for each study, and the effectiveness of the interventions categorized as positive, mixed, or no effect. A more detailed description of the positive and mixed results is presented below by specific outcome. Of the 26 studies, eleven were based in sub-Saharan Africa (five in East Africa, four in Southern Africa, one in West Africa, and one in two countries, one in South Africa and the other in West Africa); six were based in the Middle East and North Africa region; and nine took place in Asia (six in South Asia, two in East Asia, one in Central Asia). Twenty of the 26 included studies assessed health facility-based interventions. Three were focused on community interventions, two had both community and facility components, and one was a workplace program.

\section{Contraceptive knowledge}

Ten of the 26 studies assessed changes in knowledge as a result of a PPFP intervention. Eight assessed facility-based interventions, one evaluated the efficacy of a community-based intervention, and one included both facility- and communitybased components.

Of the eight facility-based interventions that included a knowledge outcome, three had statistically significant positive effects. ${ }^{20-22} \mathrm{~A}$ prevention of mother-to-child transmission (PMTCT)/PPFP integration intervention in Zimbabwe delivered provider training on PPFP counseling and IUD insertion and removal. ${ }^{21}$ The intervention consisted of three 90-minute sessions with PMTCT clients. Nurses in this study also received training on implant insertion and removal. Though at 6 weeks there was no significant difference in knowledge between the intervention and control groups, at 3 months, the difference was significant with $85.5 \%$ of the intervention and $56.3 \%$ of the controls reporting that IUD is effective at preventing pregnancy $(P=0.002)$.

The two additional facility-based interventions that increased knowledge included a partner-education component. ${ }^{20,22}$ Varkey et a ${ }^{122}$ provided individual or same-sex group counseling sessions at clinics in India at the woman's first antenatal care (ANC) visit and 6 months postpartum. The sessions were available for women and husbands who accepted their wife's invitation to attend clinic in the sites offering the "Men in Maternity" intervention. Control clinics provided routine antenatal and postnatal care. Knowledge of condoms as dual protection was higher among women in Men in Maternity sites (48\%) than control sites $(38 \%)(P<0.05)$. Knowledge of condoms as dual protection increased significantly in women in Men in Maternity sites compared to controls (chi-square $=8.7, d f=2, P=0.01$ ). More women in the Men in Maternity group (20\%) and men in Men in Maternity group (22\%) knew breastfeeding as contraception compared to their control counterparts ( $13 \%$ and $15 \%$, respectively) $(P<0.05)$. Knowledge of breastfeeding as contraception 
Table 3 Included studies by author, year, location, intervention description, and quality of the evidence

\begin{tabular}{|c|c|c|c|}
\hline $\begin{array}{l}\text { (Author, year) } \\
\text { (Country) }\end{array}$ & Intervention description & $\begin{array}{l}\text { Assessment: } \\
\text { quality of the } \\
\text { evidence* }\end{array}$ & Effectiveness \\
\hline $\begin{array}{l}\text { (Hoke et al 2014) } \\
\text { (South Africa) }\end{array}$ & $\begin{array}{l}\text { Provider training on RH services for HIV+ women; IUD insertion and } \\
\text { removal; supply management; referral system for female sterilization. }\end{array}$ & II-3, Poor & Knowledge: Mixed results \\
\hline $\begin{array}{l}\text { (Mullany et al 20I0) } \\
\text { (Nepal) }\end{array}$ & $\begin{array}{l}\text { Education: Male involvement: two } 35 \text {-minute counseling sessions } \\
\text { in a private room at hospital during ANC and a second session } \\
4-6 \text { weeks later. Group A: husband + wife; Group B: wife alone; } \\
\text { Group C: no education. }\end{array}$ & I, Good & Knowledge: Positive results \\
\hline $\begin{array}{l}\text { (Sarnquist et al 2014)21 } \\
\text { (Zimbabwe) }\end{array}$ & $\begin{array}{l}\text { Provider training in PMTCT-FP integration: three } 90 \text {-minute } \\
\text { sessions with } 12 \text { participants each. Intervention and controls } \\
\text { received care with two 5-day FP trainings in counseling, and IUD } \\
\text { and implant insertion and removal. }\end{array}$ & II-2, Fair & $\begin{array}{l}\text { Knowledge: Positive results } \\
\text { PPFP use: No effect } \\
\text { PPFP use by method type: } \\
\text { No effect } \\
\text { Intention: No effect }\end{array}$ \\
\hline $\begin{array}{l}(\text { Varkey et al 2006) } \\
\text { (India) }\end{array}$ & $\begin{array}{l}\text { Education: Male involvement: individual or same-sex group } \\
\text { counseling for women and husbands on: STIs, correct use of } \\
\text { condoms, and use as dual protection at ANC visit and } 6 \text { months PP. }\end{array}$ & II-2, Fair & $\begin{array}{l}\text { Knowledge: Positive results } \\
\text { PPFP use: Positive results } \\
\text { PPFP use by method type: } \\
\text { No effect } \\
\text { Intention: Positive results }\end{array}$ \\
\hline $\begin{array}{l}(\text { Lee et al 20II) })^{39} \\
\text { (Taiwan) }\end{array}$ & $\begin{array}{l}\text { Education: Group A received bedside health education in PP ward } \\
\text { with pamphlets, and one pamphlet to take home and telephone } \\
\text { reminders. Group B received the pamphlet only. Controls received } \\
\text { routine PP education, a I0-I5-minute talk by a nurse with a } \\
\text { pamphlet, but without interactive design. }\end{array}$ & I, Fair & $\begin{array}{l}\text { Knowledge: No effect } \\
\text { PPFP use: No effect }\end{array}$ \\
\hline $\begin{array}{l}(\text { Vance et al 2014) })^{38} \\
\text { (Ghana and Zambia) }\end{array}$ & $\begin{array}{l}\text { Integration: FP-immunization; trained vaccinators to screen for } \\
\text { pregnancy risk, provide individual counsel and referral for FP during } \\
\text { immunization visit. }\end{array}$ & I, Fair & $\begin{array}{l}\text { Knowledge: No effect } \\
\text { PPFP use: No effect }\end{array}$ \\
\hline $\begin{array}{l}(\text { Tazhibayev et al 2004) } \\
\text { (Kazakhstan) }\end{array}$ & $\begin{array}{l}\text { Providers trained to counsel on the benefits of LAM as an FP } \\
\text { method, lactation management, and breastfeeding using WHO/ } \\
\text { UNICEF I8-hour course and } 20 \text {-hour course on LAM. Compared } \\
\text { baby friendly hospitals (BFH), BFH with augmented training, } \\
\text { ordinary hospitals }(\mathrm{OH}) \text {, and } \mathrm{OH} \text { with augmented training. }\end{array}$ & II-3, Fair & $\begin{array}{l}\text { Knowledge: Mixed results } \\
\text { PPFP use: Mixed results }\end{array}$ \\
\hline $\begin{array}{l}\text { (Abdel-Tawab et al 2008) })^{33} \\
\text { (Egypt) }\end{array}$ & $\begin{array}{l}\text { Education: Group I (health services model) received birth spacing } \\
\text { messages during pre- and postnatal visits. Group } 2 \text { (community } \\
\text { awareness model) included health services model plus awareness for } \\
\text { men through community activities. Both groups received home visits } \\
\text { to PP women up to } 12 \text { months PP. Group } 3 \text { was control. }\end{array}$ & II-2, Poor & $\begin{array}{l}\text { Knowledge: No effect } \\
\text { PPFP use: Positive results } \\
\text { Occurrence of pregnancy: } \\
\text { No effect }\end{array}$ \\
\hline $\begin{array}{l}(\text { Sebastian et al 20I2) } \\
\text { (India) }\end{array}$ & $\begin{array}{l}\text { Education: Campaigns by community workers educated pregnant } \\
\text { women, mothers-in-law, and men about PPFP in intervention } \\
\text { blocks. }\end{array}$ & II-2, Fair & $\begin{array}{l}\text { Knowledge: Positive results } \\
\text { PPFP use: Positive results } \\
\text { PPFP use by method type: } \\
\text { No effect }\end{array}$ \\
\hline $\begin{array}{l}\left(\text { Adanikin et al 2013) }{ }^{26}\right. \\
\text { (Nigeria) }\end{array}$ & $\begin{array}{l}\text { Women were randomized during the third trimester in ANC: } \\
\text { receive either multiple individual counseling sessions or SOC } \\
\text { (one individual session at the 6-week postnatal check). }\end{array}$ & I, Good & $\begin{array}{l}\text { PPFP use: Positive results } \\
\text { PPFP use by method type: } \\
\text { No effect }\end{array}$ \\
\hline (“Research Findings: & Integration: FP-immunization; I 4 facilities randomized messages & II-2, Fair & PPFP use: Positive results \\
\hline
\end{tabular}
referral for FP.

Education: Couples counseling intervention group received 20-minute counseling with husband or mother-in-law in the PP ward; Measurement at 8-12 week PP follow-up

(Shaaban et al 2013 $)^{28}$ (Egypt)
Education: PP contraceptive counseling. LAM-EC group got $\mathrm{LAM}+$ counseling on EC + one free pack of EC. Advised to use only once and then initiate regular FP. LAM group: no counseling on EC or EC packet.

quality of the

evidence*

I, Good Knowledge: Positive results

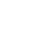


Table 3 (Continued)

\begin{tabular}{|c|c|c|c|}
\hline $\begin{array}{l}\text { (Author, year) } \\
\text { (Country) }\end{array}$ & Intervention description & $\begin{array}{l}\text { Assessment: } \\
\text { quality of the } \\
\text { evidence }\end{array}$ & Effectiveness \\
\hline $\begin{array}{l}(\text { Akman et al 20l0) } \\
\text { (Turkey) }\end{array}$ & $\begin{array}{l}\text { Education: Individual 30-minute PP contraception counseling with } \\
\text { visual aids. Controls received a leaflet during the third trimester } \\
\text { visit with questions answered at time leaflet was given. }\end{array}$ & I, Fair & $\begin{array}{l}\text { PPFP use: No effect } \\
\text { PPFP use by method type: } \\
\text { No effect }\end{array}$ \\
\hline$(\text { Dhont et al 2009) })^{34}$ & Education: Contraception counsel at each visit ANC and PP. & II-2, Fair & PPFP use: No effect \\
\hline (Rwanda) & $\begin{array}{l}\text { Women at Site A were referred to FP services where LARCs } \\
\text { were occasionally available.Women at Site B were offered }\end{array}$ & & $\begin{array}{l}\text { PPFP use by method type: } \\
\text { Positive results }\end{array}$ \\
\hline
\end{tabular}

(Huang et al 2014) $^{31}$

(People's Republic of China)

(Sahip and Turan 2007) $^{41}$

(Turkey)

(Bashour et al 2008) $^{42}$

(Syria)

(Ahmed et al 2015) ${ }^{32}$

(Bangladesh)

(Kunene et al 2004) $^{44}$

(South Africa)

(Warren et al 2008) ${ }^{45}$

(Lesotho)

(Mazia et al 2009) $^{35}$

(Swaziland)

(Warren et al 2010) ${ }^{36}$

(Kenya)

(Tawfik et al 2014) $^{37}$

(Afghanistan)

(Ayiasi et al 2015) ${ }^{46}$

(Uganda)

(Topatan and Demirci 2015) ${ }^{29}$

(Turkey) implants and IUD onsite and referred for short-acting methods.

Women at both sites were referred for sterilization. Fees varied

across methods and sites.

Education: Couple counseling on: fertility return, benefits/risks of long-

and short-acting contraception, resumption of sex, risks of unintended

pregnancy, and pamphlet. Women could receive LARCs or condoms prior

to discharge. Other modern methods available at follow-up visits.

Education: Male involvement study trained workplace doctors to

provide six education sessions of 3-4 hours each for expectant

fathers, covering maternal and child health and PPFP.

Group A received four home visits at I day, 3 days, 7 days, and

4 weeks postpartum by registered midwives with 5 days training,

including choices and plan for FP. Group B got one home visit on

day 3. Group $\mathrm{C}$ got no visit.

Service delivery: Standard of care includes home visits at pregnancy,

6 days PP, and 29-35 days PP.Additional visits in intervention arm

included home visits at 2-3 months and 4-5 months focused on PPFP.

Intervention $\mathrm{CHWs}$ provided pills, condoms, and follow-up injectables.

Education: Male involvement study included three interactive I, Poor

counseling sessions (two ANC and one at 6 weeks PP) in groups,

including an ANC booklet for women to read and share with partners.

Integration: PMTCT/FP trained nurses to provide three

consultations with checklist for mother and baby at 48 hours,

I-2 weeks, and 6 weeks.

Integration: PMTCT/FP provider training, and increased number

of consultations with mother and baby, and integrated health checks.

Integration: PMTCT/FP trained providers to conduct three

consultations with checklist for mother and baby at 48 hours,

I-2 weeks, and 6 weeks PP.

Quality: Intervention includes QI processes and a PPFP change

package, including private FP counseling space, and FP counseling

training for staff, involving husbands and mother-in-laws. Women

choosing FP referred to a private contractor for method.

Service delivery: Women presenting at ANC at intervention

clinics were followed with home visits by village health workers

and offered counseling, but not products, related to PPFP during

the prenatal period in their homes. Women presenting at ANC at

control clinics were offered routine ANC offered in the clinics.

Education: The experimental group received a training of four

sessions over 4 hours, including information on anatomy, FP, STDs,

and cancers. The control group received routine discharge training

over 30 minutes, including discussion of breastfeeding but not FP.
II-2, Fair

II-2, Fair $\quad$ PPFP use: Mixed results

I, Fair $\quad$ PPFP use: No effect

PPFP use by method type:

No effect

Occurrence of pregnancy:

No effect

PPFP use: Positive results

PPFP use by method type:

Positive results

PPFP use: No effect

PPFP use by method type:

No effect

II-3, Poor

PPFP use by method type:

Mixed results

Intention: Negative results

II-3, Fair Intention: Positive results

II-3, Fair Intention: Positive results

II-2, Fair Occurrence of pregnancy:

Positive results

I, Fair

PPFP use: No effect

Occurrence of pregnancy:

No effect

II-I, Fair

PPFP use: Positive results

Notes: *We assessed the risk of bias according to the domains in the Newcastle-Ottawa Scale for nonrandomized studies and the Cochrane Handbook for randomized controlled trials. These domains included: study design (selection, assignment, and comparability of comparison and control groups), attrition, spillover and contamination, quality of intervention description and implementation, representativeness of the study groups, and sample size. We used the US Preventive Services Task Force to assign the strength of study design. Taken together, the US Preventive Services Task Force classification and risk of bias assessment were used to identify the quality of the evidence presented in each included study.

Abbreviations: ANC, antenatal care; EC, emergency contraception; FP, family planning; IUD, intrauterine device; LAM, lactational amenorrhea method; PMTCT, prevention of mother-to-child transmission; PP, postpartum; PPFP, postpartum family planning; UNICEF, United Nations International Children's Emergency Fund; WHO, World Health Organization; RH, reproductive health; STI, sexually transmitted infection; SOC, standard of care; CHWs, community health workers; QI, quality improvement; STDs, sexually transmitted diseases. 
increased in women in the Men in Maternity group compared to controls (chi-square $=5.4, d f=1, P=0.02$ ). In Nepal, Mullany et $\mathrm{al}^{20}$ evaluated an intervention consisting of two 35-minute counseling sessions during ANC and at 4-6 weeks postpartum. This three-arm study provided education for husband and wife together, or the wife alone, while no one in the third arm received PPFP education. In couples educated together, women were more likely than women in the no-education group (unadjusted relative risk [RR] 1.08 [95\% confidence interval $\{\mathrm{CI}\}: 1.01-1.16])$ and the women-only education group (unadjusted RR 1.11 [1.03-1.20]) to know at least one FP method. There was no difference between women educated alone versus no education (unadjusted RR 0.97 [95\% CI: 0.88-1.06]).

Two facility-based studies resulted in mixed effects. In South Africa, ${ }^{23}$ where providers received supply management training, referral system support, and referral training for female sterilization, the results were mixed with some but not all indicators achieving positive results. PMTCT client knowledge of sterilization increased from $75.8 \%$ to $83.8 \%$ $(P=0.022)$. However, there were significant decreases in the proportion of women who knew HIV-positive women can use IUD.

In Kazakhstan, researchers trained maternity staff to provide patient counseling on the benefits of LAM with a 20-hour training and counseling course. ${ }^{24}$ The intervention was implemented in four hospitals, two of which were previously certified as baby friendly hospitals (BFHs) according to the WHO/United Nations Children's Fund standards, and two were not certified BFH, so they were considered ordinary hospitals (OHs). Of the five matched control group hospitals, two were BFHs and three were OHs. Knowledge of LAM was $97.3 \%$ in intervention $\mathrm{BFH}$ and $81.4 \%$ in control $\mathrm{BFH}$ $(P<0.0001)$, but significantly higher in the control OH $(79 \%)$ than the intervention $\mathrm{OH}(71.3 \%)(P<0.0001)$. The proportion of women with LAM knowledge in intervention BFH was significantly higher than in intervention $\mathrm{OH}$. Knowledge of IUD, pills, injectables, sterilization, and implants varied by the type of hospital and intervention or control, and results were mixed. In general, delivering in a BFH with the intervention increased a woman's chances of knowing these methods compared to an intervention $\mathrm{OH}$.

One community-based intervention with positive effects on PPFP knowledge used community workers to educate pregnant women, mothers-in-law, and men about PPFP in intervention areas. ${ }^{25}$ Control areas received activities provided by the government-run program, but no intervention activities. Knowledge of healthy timing and spacing messages was higher in the intervention group (unadjusted odds ratio [OR] 2.18, adjusted OR [AOR] 2.07) $(P<0.01$ for both OR and AOR), as was knowledge of more than two spacing methods (unadjusted OR 2.06, AOR 1.96) $(P<0.01$ for both OR and AOR).

\section{PPFP use}

Nineteen of the included studies assessed PPFP use. Among these, 14 assessed facility-based interventions, three assessed community-based strategies, two interventions had facility and community components, and one was a workplace intervention.

Of the 19 studies that assessed PPFP use, ten had significantly positive results. All seven of the facility-based interventions with positive results included a counseling component, though they varied in how, where, and to whom the counseling was delivered. Adanikin et $\mathrm{al}^{26}$ assessed the difference among multiple, individual antenatal counseling, and one-time postnatal counseling on PPFP use among women visiting a large teaching hospital in Nigeria. Women were randomized during the third trimester in ANC to receive either the opportunity for multiple individual counseling sessions before childbirth or the standard of care, one individual session at 6 weeks postpartum. Though the antenatal counseling group (77.2\%) and postnatal counseling group $(67.7 \%)$ did not differ significantly in PPFP use of any method $(P=0.130)$, the antenatal group was less likely to use traditional methods $(19.8 \%)$ compared to the postnatal counseling group (32.3\%) $(P=0.044)$, and more likely to use a modern method (ANC $57.4 \%$ vs postnatal care $35.4 \%$ ) $(P=0.002) .{ }^{26}$

In Rwanda, Dulli et al (2012) $)^{27}$ assessed the effectiveness of an integrated FP-immunization intervention on PPFP use. Immunization providers in the intervention facilities were trained to provide group counseling, distribute brochures, assess pregnancy risk according to LAM criteria, and refer those at risk for pregnancy to colocated FP services. Control sites did not integrate FP into immunization services. In FP/ immunization sites, PPFP increased from 49\% at baseline to $57 \%$ at 16 -month follow-up postintervention. In control sites, there was a decrease in PPFP from $58 \%$ at baseline to $51 \%$ at 16 -month follow-up. The $15 \%$ difference between the intervention and control sites was significant $(P<0.05){ }^{27}$

Shaaban et $\mathrm{al}^{28}$ randomly assigned women who delivered in a teaching hospital in Egypt to a LAM-emergency contraception (EC) group or a LAM-only group. Both groups received postpartum contraceptive counseling and LAM counseling, including that they should transition to a modern 
method after one or more criteria of LAM expired. The LAM$\mathrm{EC}$ women received counseling on $\mathrm{EC}$ and one free packet of EC pills. At 6 months, the LAM-EC group used a modern method of PPFP significantly more than the LAM-only group $62\left(73.4 \%\right.$ vs $45.2 \%$, respectively) $(P=0.0001) .{ }^{28}$

In Turkey, a group of adolescents aged 15-19 were allocated to the experimental group, which received a training of four sessions over 4 hours, including information on anatomy, FP, sexually transmitted diseases (STDs), and cancers. A control group of adolescents received routine discharge training over 30 minutes, including discussion of breastfeeding but not FP. At 3 months postpartum, 20\% of adolescents in the experimental group and $10.9 \%$ of control adolescents were using a modern method of contraception, though this was statistically insignificant. At 9 months, the proportions were $50.9 \%$ and $30.4 \%$, respectively, and at 12 months, $58.2 \%$ and $28.3 \%$, respectively $(P<0.05){ }^{29}$

The three additional facility-based interventions that increased PPFP use included a partner-education component. .2,30,31 Saeed et $\mathrm{al}^{30}$ randomly assigned women admitted to the labor ward after delivery in a hospital in Pakistan. One group received a 20 -minute counseling session with the husband or mother-in-law present if possible, and received a leaflet. The other group received no counseling or leaflets. Both groups were asked to return in 8-12 weeks. The couples counseling group women had significantly higher PPFP use (56.9\%) than the control group women $(6.31 \%)$ at their postpartum visit $(P<0.01)$. Varkey et $\mathrm{al}^{22}$ provided individual or same-sex group counseling sessions for women and the husbands who chose to attend at an ANC visit and 6 months postpartum (described in the "Knowledge" section). Control clinics provided routine antenatal and postnatal care. Significantly more women in the counseling group (58.5\%) than controls (45\%) $(z=2.70$, $P<0.05)$ and men in the counseling group $(64.5 \%)$ than controls (47.8\%) $(z=3.39, P<0.05)$ reported current PPFP (even after controlling for parity). In Huang et al, ${ }^{31}$ the intervention included couples counseling for women delivering in a health center and their partners. Counseling included information on fertility return, benefits and risks of long and short-acting contraception, resumption of sex, risks of unintended pregnancy, and written material. Women could opt to receive long-acting reversible contraceptions (LARCs) or condoms prior to discharge. Other modern methods were available at follow-up visits. The intervention cohort had a higher prevalence of contraceptive use than the two nonintervention groups at the end of first year postpartum (97\% vs $73.6 \%$ and $62.9 \%$, respectively)
$(P<0.0001)$. Use of contraception overall, Depot Medroxyprogesterone Acetate (DMPA), IUD, and sterilization all increased significantly between 6 weeks and 12 months among intervention women.

Two community-based efforts showed positive results. Sebastian et $\mathrm{al}^{25}$ (described above in the "Knowledge" section) included a behavior change communication program integrated into the existing government community health worker program in India. Control areas received the standard government messaging from community health workers. Intervention-area community workers educated women, men, and mothers-in-law on healthy timing and spacing of pregnancy, LAM, and PPFP using communication materials. Modern PPFP use was significantly higher in intervention areas $(57 \%)$ than control areas $(30.1 \%)(P<0.01)$. Women in intervention areas were significantly less likely to use no method at 9 months $(24.1 \%)$ compared to women in control areas $(44.6 \%)(P<0.01)$, and less likely to use traditional methods $(18.95 \%)$ than women in control areas $(25.3 \%)$ $(P<0.01)$.

In Bangladesh, standard of care includes home visits at pregnancy, 6 days postpartum, and 29-35 days postpartum. ${ }^{32}$ The intervention included additional home visits at 2-3 months and 4-5 months postpartum, with counseling and provision of contraception. At 3 months, 36.4\% of the intervention group who received additional home visits postpartum and $10.8 \%$ of the comparison group that received standard of care were using any method of contraception $(P<0.0001)$. At 12 months, these proportions were $42.1 \%$ and $27.1 \%$, respectively $(P<0.0001)$. At 24 months, $46.1 \%$ of intervention areas and $34.9 \%$ of control areas reported any method use $(P<0.0001)$. The standard of care areas also saw substantial change over time in contraceptives use. The proportion of use in intervention areas was significantly higher than in control areas, but even in control areas, use increased and did so quickly.

The three-arm cohort study in Egypt by Abdel-Tawab et $\mathrm{al}^{33}$ (described above in the "Knowledge" section) included both facility- and community-based components. At 4 months, more women in the group that received birth spacing messages during pre- and postnatal visits at the health facility $(50.2 \%)$ were using FP than in the group that included these sessions plus awareness for men through community activities (35.9\%) or the control (no facility-based counseling or community awareness activities) (32.7\%) $(P<0.05)$. At 10-12 months, more women in health services group $(42.1 \%)$ and community group (33.2\%) were using FP than control $(25.8 \%)(P<0.01)$. 


\section{PPFP use by method type}

Twelve of the included studies assessed use of PPFP by type of method. Four had significant positive results: three were facility-based studies and one was community-based.

Shaaban et $\mathrm{al}^{28}$ found that at 6 months, significantly more women in the LAM-EC group (30\%) were using IUD than women in the LAM-only group (19.8\%) $(P=0.0001)$. Saeed et $\mathrm{al}^{30}$ found that their couples counseling group, who received 20-minute counseling with the husband or mother-in-law if possible in the postpartum ward, was more likely to use pills $(37.1 \%)$ than the group who did not receive counseling or a leaflet $(6.3 \%)(P<0.01)$. Dhont et $\mathrm{al}^{34}$ found higher injectable use among women at Site A, who were referred for all FP services to a public clinic that was typically stocked with short-acting methods (64\%), than among women at Site B, who were offered implants and IUDs on-site, with referrals for short-acting methods (27\%) $(P<0.001)$. Women at Site B used implants more frequently $(38 \%)$ than women at Site A $(6 \%)(P<0.001)$. Women attending Site B (with on-site access to LARCs) were 10.2 times more likely to start using implants ( $95 \%$ confidence interval 5.0-20.8) than those attending Site A, who may not have had consistent stock of LARCs but had more consistent stock of short-acting methods.

In Bangladesh, Ahmed et a ${ }^{32}$ demonstrated that additional postpartum home visits that focused on FP led to increased use by method. At 3 months, $22.8 \%$ of women in the intervention areas and $0 \%$ of women in the areas that received the standard of care were using LAM $(P<0.0001)$. At 6 months, the proportions were $11.9 \%$ and $0 \%$, respectively. At 3 months, women in intervention areas were using significantly more injectable contraceptives than women in the standard of care areas $(4.6 \%$ vs $2.8 \%, P=0.0025)$; however, there was no difference in injectable use at 12 or 24 months. At 3 months, $4.4 \%$ of women in the standard of care areas and $3.2 \%$ of women in the intervention areas were using pills $(P=0.047)$; however, at 12 months and 24 months, a significantly higher proportion of intervention women $(20.3 \%$ and $20 \%$, respectively) used pills than women in the standard of care group (10.6\% at 12 months and $15 \%$ at 24 months).

\section{Intention to use PPFP}

Six facility-based studies assessed a change in the intention to use FP during the postpartum period. Four demonstrated significant positive results.

Two PMTCT-FP integration studies showed a positive effect of provider training, counseling, an increased number of consultations with mother and baby, and integrated health checks for mother and baby on intention to use FP. Both conducted direct provider-patient interactions, measuring whether or not women went home with their preferred contraceptive method. Provider-patient interactions were observed during the 6-week follow-up consultation. Direct observation of client-provider interactions in Swaziland showed a significant increase from pre- to postintervention in client receipt of preferred contraceptive method from $28 \%$ to $70 \%(P<0.01) .{ }^{35}$ In Kenya, there was a significant increase in women choosing a PPFP method at 6 weeks from preintervention (35\%) to postintervention (63\%) (no $P$-value reported). ${ }^{36}$

The other two studies involved couples counseling, or counseling with the woman and a close relative. Saeed et a ${ }^{30}$ (described above in PPFP use) provided a 20 -minute couples counseling session and a leaflet for the intervention group, while the comparison group did not receive counseling or a leaflet. Both groups were told to return in 8-12 weeks. Intention to use PPFP after 6 months was significantly different for the intervention group (5\%) versus the group that did not receive counseling or educational materials $(28.2 \%)$ $(P<0.01)$. Both In India, Varkey et $\mathrm{a}^{22}$ found that of women not using FP at 6-8 months postpartum, $84 \%$ of the women who received same sex or group counseling and brochures for women and husbands during ANC, and $65.6 \%$ of women who did not receive counseling or a brochure, intended to use FP in the future $(z=3.12, P<0.05)$.

\section{Occurrence of pregnancy}

Six studies measured occurrence of pregnancy as an outcome of the intervention. Two had significant positive results for occurrence of pregnancy. Both were facility-based interventions.

Shaaban et $\mathrm{al}^{28}$ (described in "PPFP use") found significantly fewer self-reported pregnancies at 6 months in the LAM-EC group (0.8\%) than the LAM-only group (2.6\%) $(P=0.0005)$. Tawfik et a ${ }^{37}$ randomly selected women from two hospitals in Afghanistan to receive either PPFP counseling in the maternity ward before discharge or standard postpartum care, which means they did not receive systematic PPFP counseling. This intervention was a substudy of a larger PPFP quality improvement effort. FP counselors followed women by phone at 3, 6, 12, and 18 months to obtain PPFP use and pregnancy data, and to repeat PPFP messages to women in the counseling group. Self-reported pregnancy at 3 months was not significantly different between the counseling $(0 \%)$ and standard of care (SOC) groups $(2.6 \%)$ (no $P$-value reported). At 6 months, the difference between the 
counseling (2.8\%) and SOC groups (14.5\%) was significant $(P<0.001)$. At 12 months, there was a significant difference in pregnancy between the counseling (5.8\%) and SOC groups $(21.9 \%)(P<0.001)$. At 18 months, the difference between the counseling (14.1\%) and SOC groups (43.7\%) remained significant $(P<0.001){ }^{37}$

\section{Discussion}

The studies reviewed represented well the different parts of the developing world. However, they differed in quality, which might have affected the results.

\section{Quality of the evidence}

Eight of the 26 included studies randomly allocated participants to an intervention or control condition. Eight likewise assessed baseline comparability between groups and found no statistically significant differences between them. Most studies adequately described the intervention, although often researchers noted that there were issues with fidelity of implementation. Only seven studies described their power calculation. Of the 18 studies that followed the same cohort(s) over time, only three failed to achieve $20 \%$ attrition or better, which is considered good for contraceptive research.

Because we considered both randomized and nonrandomized studies, the grade levels of evidence quality span from high to low, with most studies falling in the moderate range (see Table 3 ). Overall, we considered the quality of the evidence to be moderate. Only three studies were categorized as Type I, Good. ${ }^{20,26,28}$ All three demonstrated positive effects: Adanikin et $\mathrm{al}^{26}$ and Shaaban et $\mathrm{al}^{28}$ showed significant increases in postpartum use among women who received the intervention, and Mullany et $\mathrm{al}^{20}$ impacted knowledge of contraception. We can speculate from these studies that PPFP counseling during ANC on both LAM and other modern methods impacts both knowledge and use of PPFP. Inclusion of male partners may produce more extreme results. Providing free EC packets and counseling at hospital discharge is a practice worth replicating in other contexts outside Egypt. ${ }^{28}$

\section{Knowledge}

Of the studies that assessed knowledge, three were Type I studies with good or fair rating. ${ }^{20,38,39}$ Of these three, only Mullany et $\mathrm{al}^{20}$ (Type I, Good) demonstrated significantly positive results for knowledge. The researchers' most significant findings at 4 to 6 weeks follow-up were among couples that were educated together, compared to women educated alone and women receiving no education. This study recruited and randomly allocated women whose husbands were with them at the health facility for an ANC check into each study arm. In short, though the study was of high quality and the results are compelling, the results are not generalizable to women whose husbands do not attend ANC with their wives.

Three Type II-2 studies with fair quality showed significant positive effects. ${ }^{21,22,25}$ All three interventions included a counseling component. The highest quality study ${ }^{20}$ and two of the Type II-2 studies ${ }^{22,25}$ included men in PPFP education. In Varkey et al, ${ }^{22}$ the intervention group had more significant increases in PPFP knowledge among both men and women at 6 months, though due to the intervention design, we do not know if this is an effect of the counseling sessions or a synergistic effect of counseling and having a partner who has also been educated. This study had loss to follow-up rates of $62 \%$ in the control and $56 \%$ in the intervention groups, casting doubt on the generalizability of the results.

Overall, the quality of the evidence for studies assessing knowledge as an outcome ranged from poor to high, with the highest quality trials leading to mixed results. These findings are aligned with a previous review of the effects of counseling on PPFP (Lopez et al 2012). There is some evidence that facility- and community-based interventions can have a significantly positive effect on knowledge outcomes. The study with the longest follow-up period of 9 months ${ }^{25}$ indicates that community-based education may have a sustained impact on PPFP knowledge. Further research that follows participants for 9 months or more is needed. Considering the limitations noted above, it would be difficult to generalize the results of these studies to other contexts.

Finally, knowledge about return to fertility may be a contributing factor to delays in initiating postpartum contraception. ${ }^{5}$ However, fertility knowledge was not included as an outcome in any of the included studies. Considering the potential importance of this factor for improving PPFP use, there is a clear gap in the evidence responding to increasing women's understanding of the risk of pregnancy before return to menses in LMIC.

\section{PPFP use}

Of the ten studies demonstrating a positive effect on PPFP use, nine were of fair or good Type I or Type II-2 quality. The studies that did not demonstrate significant results on use were of comparable quality. These mixed results make it challenging to make definitive conclusions from the literature. Adanikin et $\mathrm{a}^{26}$ demonstrated that opportunities for multiple individual ANC counseling sessions were more effective than a single postnatal counseling session. However, 
Dhont et $\mathrm{al}^{34}$ offered ANC and postpartum counseling to women with a referral to onsite LARCs or offsite short-acting methods, and did not see an effect. The latter study may have had better results with on-site short-acting methods that are more popular in Rwanda. Akman et $\mathrm{al}^{40}$ showed no difference between in-person postnatal counseling and a leaflet sent home with women in Turkey. This same study in a less literate community may have had more decisive results. In Lee et $\mathrm{al}^{39}{ }^{39}$ there was no difference between the interactive in-person postnatal counseling and standard of care postnatal counseling, indicating that perhaps it is engaging with a knowledgeable person, and not the written materials or interactive nature of the educational model, which makes a difference in PPFP use.

Both Dulli et al ${ }^{27}$ (Type II-2, Fair) and Vance et $\mathrm{al}^{38}$ (Type I, Fair) assessed an $\mathrm{FP}$-immunization integration program in sub-Saharan African contexts. Vance et $\mathrm{al}^{38}$ note that the intervention may not have been implemented as intended, with providers conducting group rather than individual counseling, though the larger issue may have been inconsistent implementation. Interestingly, Dulli et $\mathrm{al}^{27}$ purposefully implemented group counseling and saw significant effects on PPFP use. Further research on immunization services as a platform for PPFP counseling and referral, and specific design elements of such an intervention, is needed.

Male partner involvement in facility settings was successful in both the studies by Saeed et $\mathrm{al}^{30}$ and Varkey et al. ${ }^{22}$ The former had a very short follow-up period of only 8-12 weeks, while the latter had high loss to follow-up rates, limiting generalizability. The workplace intervention to educate men notes that the sample is insured, has easy access to reproductive health services, and $90 \%$ of them already practice some form of PPFP use, indicating that the study sample may not be representative of the general population. ${ }^{41}$ Workplace interventions targeting men in other contexts may be impactful and more research is needed.

The Shaaban et $\mathrm{al}^{28}$ strategy (Type I, Good) of disseminating postpartum contraceptive counseling, LAM counseling, and EC counseling with a free packet of EC to significantly increase the use of other modern methods of PPFP, besides $\mathrm{EC}$, is unique in the literature. This approach may be costprohibitive in other regions, but may be worth additional demonstration studies with cost-effectiveness analysis in other contexts.

At the community level, we see mixed results. Sebastian et $\mathrm{al}^{25}$ demonstrate that integrating PPFP messages into an existing functional community health worker program in India is effective. On the other hand, Bashour et $\mathrm{al}^{42}$ did not find home visits to be effective. A critical difference was the former project's emphasis on educating women, men, and mothers-in-law, while the latter focused on women. Finally, Syria does not have a community midwife cadre, and so selected facility-based midwives to carry out the intervention. The researchers note that community practice differs substantially from facility practice, and the midwives may not have had the capabilities necessary for an effective community-based intervention. Though demonstrating significant results, Abdel-Tawab et $\mathrm{al}^{33}$ note several difficulties, including challenges with supervision, training, and implementation failures. Contexts with existing community practice may find PPFP message and referrals from community health workers for women, men, and older female relatives an effective way to increase PPFP use.

Several strategies may improve PPFP use. Counseling, partner involvement, integration with the immunization platform, and community awareness that engage women, men, and older female relatives may be effective in increasing PPFP uptake. However, the number and timing of counseling sessions are still open for debate. The main drawback with the overall findings is generalizability. Of the studies described here, only two ${ }^{25,41}$ did not draw their samples from women delivering, attending ANC, or seeking immunization for her child at a health facility. Many of the studies were based at large hospitals. There is a need for greater research on community-based programs aiming to scale up PPFP use and research that draws their sample from women who deliver outside facilities.

\section{Intention to use PPFP}

The studies that assessed women's intention to use PPFP were split between four PMTCT-FP integration and two male involvement interventions. The study with the highest quality of evidence ${ }^{30}$ (Type-I, Fair) involved husbands or close relatives in the counseling sessions, and distributed a leaflet to women in the counseling (versus no counseling) group. This intervention may be generalizable to other women who deliver in facilities in major urban areas, such as Islamabad. The study design does not allow us to conclude whether it was the counseling, leaflet, male involvement, or some combination of these factors that had the most impact on PPFP use intention, and so more research is needed. Determining the keystone element of this intervention would also aid in deciding other contexts that may be amenable to this intervention. For example, a leaflet may or may not be useful in areas of high illiteracy. 
Of the two other studies with the highest quality of evidence $^{21,22}$ (Type II-2, Fair), one had positive and the other had null results. Sarnquist et $\mathrm{al}^{21}$ were able to demonstrate increases in PPFP knowledge, but not use or intention to use condoms. Part of the intervention included provider training, which was completed at all clinics in the study area, including those that acted as nonintervention controls. This may have reduced the difference in the effect size found among women attending intervention and nonintervention clinics. Varkey et $\mathrm{a}^{22}$ found significantly more women who received integrated FP-sexually transmitted infection (STI) counseling intended to use FP than those who did not, but did not find a difference among the male partners who were involved in the study. Qualitative research may reveal whether different counseling messages could increase the numbers of women, couples, and men who report intention to use PPFP.

The PMTCT/FP studies with positive results ${ }^{35,36}$ were graded as having Type II-3, Fair quality of evidence. It is unclear whether it was the provider training, intervention delivery, or an effect of having a researcher directly observing provider-client interactions that may have had an effect on women's reported intentions. It seems that PMTCT-FP integration strategies that have a provider training and counseling component may be successful at efforts to increase the intention to use FP. Involving men or close female relatives in counseling efforts may also have an effect. More research is needed to understand what it is about these interventions that lead to their success, and whether intention leads to uptake.

\section{Occurrence of pregnancy}

Finally, of the studies that measured occurrence of pregnancy, Shaaban et $\mathrm{al}^{28}$ had the highest level of quality (Type I, Good). Approximately $80 \%$ of the pregnancies in this study were reported as unplanned among women who reported breastfeeding for contraception. These pregnancies should be considered failed LAM. Tawfik et $\mathrm{al}^{37}$ was of moderate quality (Type II, Fair). The researchers did not collect information on whether reported pregnancies were unplanned or unwanted. The initial sample was a random draw of women at the two hospitals, but follow-up samples were derived from the cohort that was successfully contacted previously, limiting the generalizability of their results. It is difficult to discern what aspects of the intervention - provider training, counseling messages, or the overall quality improvement initiative - had an impact on pregnancy rates. Limitations of all four studies include that they relied on self-report of pregnancy, and the samples were likely too small to allow for statistical reliability, making it difficult to draw conclusions about the effects of these interventions on pregnancy rates. However, the provision of a free packet of EC at hospital discharge, along with PPFP and LAM counseling, may be effective at reducing pregnancy over 6 months. Future studies that assess the efficacy of each of the components of the quality improvement plus PPFP counseling intervention may reveal which elements impact pregnancy rates at 3, 6, 12, and 18 months. Research on community-based interventions and interventions in Africa is needed.

\section{Contribution to the knowledge base}

This paper builds on previous reviews, and in many cases substantiates earlier conclusions with more recent findings. Koblinsky ${ }^{8}$ outlined three program models with a communitybased component: home visits by skilled clinicians, home visits by community workers, and home visits with a referral mechanism back to the health facility. Research on PPFP interventions in the last 10 years included very few programs with a community component, and the strength of the study designs was moderate. Only four studies included here tested community-based programs, and one was based in a health facility with a community outreach component. Rigorous research that assesses the efficacy and cost-effectiveness of community-based PPFP programs is needed, particularly in areas with low facility-based delivery and postnatal care.

The findings presented here augment Vernon's review ${ }^{9}$ with an assessment of the quality of the most current evidence for the programmatic strategies he describes. The most rigorous study on antenatal counseling on FP demonstrated positive results, ${ }^{26}$ but other, less meticulous studies had no or mixed effects. Overall, we found the evidence on male involvement to be high to moderate and encouraging of programs that seek to engage men in FP. ${ }^{20,22}$ Results of efforts to integrate FP and PMTCT or immunization services were mixed, with the studies with the strongest designs having both no effect ${ }^{38}$ and positive effects. ${ }^{27}$ Several interventions to promote FP at the postnatal visit had positive results. ${ }^{28,30,37}$ In general, this review provides some evidence for pursuing the strategies outlined in Vernon's overview of programs.

This review adds to the reviews by Sonalkar et $\mathrm{al}^{13}$ and Cleland et $\mathrm{al}^{14}$ that conclude there is promising evidence that programs can increase contraceptive use. Like Cleland et al, ${ }^{14}$ we found mixed results for integration of FP services and products with other health service delivery points, but agree that future research should focus not on proving the efficacy of this strategy but rather on identifying ways to optimize it. All three of these reviews - Sonalkar et al, ${ }^{13}$ Cleland et al, 
and the review presented here - are comprised primarily of interventions delivered at health facilities. Cleland et al conclude that local factors will impact the delivery and success of community-based interventions, making extant studies difficult to generalize. We argue that though this is true, a broader base of knowledge about community-based efforts to improve postpartum contraception, even from diverse regions in LMICs, would be useful in developing a knowledge base for policy and programmers.

In general, more research is needed to create a strong evidence base for PPFP interventions in various contexts and with a variety of different populations. Only six of the 19 studies with Type I or Type II Good or Fair quality were based in sub-Saharan Africa, which has the highest unmet need for FP of the major global regions. ${ }^{43}$ Moreover, the vast majority of PPFP intervention studies focus on facility-based populations, whether in ANC, labor and delivery, or the postpartum ward. Yet, many women in low- and middleincome countries still deliver at home without substantial contact with the formal health system. Evidence on promising practices, such as integration of PPFP counseling and product delivery within immunization services, is mixed, and further study of the mechanisms by which to deliver messages and how and whether to integrate product provision or only messaging is warranted. Well-designed studies at the community level are exceedingly important. Our search found only three interventions with a community component that had a Type I or II Good or Fair level of evidence.

\section{Conclusion}

PPFP is critical for birth spacing, and thus for the health of women, infants, and children. Every woman should have access to her preferred method of contraception for spacing or limiting births. Whether pregnancies are intended or unintended, every woman should be able to use contraception during the postpartum period if she chooses, in order to promote her own and her family's health.

The most substantial implication of the evidence reviewed here is that policies, programs, and the FP research agenda ought to focus on postpartum women. By targeting this period alone, PPFP prevalence could increase substantially due to the sheer number of pregnancies taking place in low- and middle-income countries. However, there continues to be a moderate level of evidence for counseling interventions on PPFP knowledge and use. ${ }^{11}$ Furthermore, male partner involvement, integration with other service delivery platforms, such as PMTCT and immunization, and innovative product delivery programs may increase knowledge and use, and decrease pregnancy rates during the postpartum period. Community-based and workplace strategies need a much stronger base of evidence to prompt recommendations. In short, we ought to prioritize reaching all women with messages, methods, and sustained FP programs. To accomplish this goal, we are calling for a stronger base of evidence that targets women in their homes, communities, workplaces, and health facilities.

\section{Disclosure}

The authors report no conflicts of interest in this work.

\section{References}

1. Singh S, Darroch JE. Adding It Up: Costs and Benefits of Contraceptive Services. New York: Guttmacher Institute and United Nations Population Fund; 2014.

2. Singh S, Darroch JE. Adding It Up: Costs and Benefits of Contraceptive Services Estimates for 2012. New York: UNFPA, Guttmacher Institute; 2012.

3. Sedgh G, Singh $\mathrm{S}$, Hussain R. Intended and unintended pregnancies worldwide in 2012 and recent trends. Stud Fam Plann. 2014;45(3): 301-314.

4. Andreev K, Kantorova V, Bongaarts J. United Nations Population Division, Department of Economic and Social Affairs; 2015. Available from: http://www.un.org/en/development/desa/population/publications/ technical/2013-3.shtml. Accessed June 4, 2015.

5. Borda MR, Winfrey W, McKaig C. Return to sexual activity and modern family planning use in the extended postpartum period: an analysis of findings from seventeen countries. Afr J Reprod Health. 2010; 14(4 Spec no):72-79.

6. Ahmed S, Li Q, Liu L, Tsui AO. Maternal deaths averted by contraceptive use: an analysis of 172 countries. Lancet. 2012;380(9837): $111-125$.

7. WHO. WHO Programming Strategies for Postpartum Family Planning. Geneva: WHO; 2013. Available from: http://www.who.int/reproductivehealth/publications/family_planning/ppfp_strategies/en/. Accessed June 4, 2015.

8. Koblinsky MA. Community-Based Postpartum Care: an Urgent Unmet Need. Washington, DC: USAID, CATALYST Consortium; 2005.

9. Vernon R. Meeting the family planning needs of postpartum women. Stud Fam Plann. 2009;40(3):235-245.

10. Yeakey MP, Muntifering CJ, Ramachandran DV, Myint Y, Creanga AA, Tsui AO. How contraceptive use affects birth intervals: results of a literature review. Stud Fam Plann. 2009;40(3):205-214.

11. Lopez LM, Grey TW, Hiller JE, Chen M. Education for contraceptive use by women after childbirth. Cochrane Database Syst Rev. 2010;(1):CD001863.

12. Arrowsmith ME, Aicken CR, Saxena S, Majeed A. Strategies for improving the acceptability and acceptance of the copper intrauterine device. Cochrane Database Syst Rev. 2012;3:CD008896.

13. Sonalkar S, Mody S, Gaffield ME. Outreach and integration programs to promote family planning in the extended postpartum period. Int $J$ Gynaecol Obstet. 2014;124(3):193-197.

14. Cleland J, Shah IH, Daniele M. Interventions to improve postpartum family planning in low- and middle-income countries: program implications and research priorities. Stud Fam Plann. 2015;46(4): 423-441.

15. Moher Da, Liberati A, Tetzlaff J, Altman DG; The PRISMA Group. Preferred reporting items for systematic reviews and meta-analyses: the PRISMA statement. PLoS Med. 2009;6(7):e1000097.

16. Meline T. Selecting studies for systematic review: inclusion and exclusion criteria. Contemp Issues Commun Sci Disord. 2006;33:21-27. 
17. Wells GA, Shea B, O'Connell D, et al. The Newcastle-Ottawa Scale (NOS) for Assessing the Quality of Nonrandomised Studies in Meta-Analyses; 2014. Available from: http://www.ohri.ca/programs/ clinical_epidemiology/oxford.asp. Accessed December 9, 2012.

18. Higgins JPT, Green S. Cochrane Handbook for Systematic Reviews of Interventions (Version 5.1.0); 2011. Available from: http://handbook. cochrane.org/. Accessed December 8, 2014.

19. Harris RP, Helfand M, Woolf SH, et al. Methods Work Group, Third US Preventive Services Task Force. Current methods of the US preventive services task force: a review of the process. Am J Prev Med. 2001; 20(3 Suppl):21-35.

20. Mullany LC, Lee TJ, Yone L, et al. Impact of community-based maternal health workers on coverage of essential maternal health interventions among internally displaced communities in eastern Burma: the MOM project. PLoS Med. 2010;7(8):e1000317.

21. Sarnquist CC, Moyo P, Stranix-Chibanda L, Chipato T, Kang JL, Maldonado YA. Integrating family planning and prevention of mother to child HIV transmission in Zimbabwe. Contraception. 2014;89(3): 209-214.

22. Varkey LE, Mishra A, Ottolenghi E, Khan ME, Das A. Integrating FP and STI prevention messages into antenatal and postnatal care: did it make a difference? Presented at: The Population Association of America 2006 Annual Meeting, Los Angeles, CA; 2006.

23. Hoke T, Harries J, Crede S, et al. Expanding contraceptive options for PMTCT clients: a mixed methods implementation study in Cape Town, South Africa. Reprod Health. 2014;11:3.

24. Tazhibayev S, Sharmanov T, Ergalieva A, Dolmatova O, Mukasheva O. Promotion of Lactation Amenorrhea Method Intervention Trial, Kazakhstan. POPLINE.org. Washington, DC; 2004. Available from: http://www.popline.org/node/236016. Accessed September 9, 2015.

25. Sebastian MP, Khan ME, Kumari K, Idnani R. Increasing postpartum contraception in rural India: evaluation of a community-based behavior change communication intervention. Int Perspect Sex Reprod Health. 2012;38(2):68-77.

26. Adanikin AI, Onwudiegwu U, Loto OM. Influence of multiple antenatal counselling sessions on modern contraceptive uptake in Nigeria. Eur J Contracept Reprod Health Care. 2013;18(5):381-387.

27. Research Findings: Integration of Postpartum Family Planning with Child Immunization Services in Rwanda; 2013. Research Triangle Park, NC: FHI360.

28. Shaaban OM, Hassen SG, Nour SA, Kames MA, Yones EM. Emergency contraceptive pills as a backup for Lactational Amenorrhea Method (LAM) of contraception: a randomized controlled trial. Contraception. 2013;87(3):363-369.

29. Topatan S, Demirci N. The efficiency of reproduction health education given to adolescents during the postpartum period. J Pediatr Adolesc Gynecol. 2015;28(5):297-303.

30. Saeed GA, Fakhar S, Rahim F, Tabassum S. Change in trend of contraceptive uptake - effect of educational leaflets and counseling. Contraception. 2008;77(5):377-381.

31. Huang Y, Merkatz R, Zhu H, et al. The free perinatal/postpartum contraceptive services project for migrant women in Shanghai: effects on the incidence of unintended pregnancy. Contraception. 2014;89(6): $521-527$.
32. Ahmed S, Ahmed S, McKaig C, et al. The effect of integrating family planning with a maternal and newborn health program on postpartum contraceptive use and optimal birth spacing in rural Bangladesh. Stud Fam Plann. 2015;46(3):297-312.

33. Abdel-Tawab N, Loza S, Zaki A. Helping Egyptian Women Achieve Optimal Birth Spacing Intervals through Fostering Linkages between Family Planning and Maternal/Child Health Services. Washington, DC: USAID; 2008.

34. Dhont N, Ndayisaba GF, Peltier CA, Nzabonimpa A, Temmerman M, van de Wijgert J. Improved access increases postpartum uptake of contraceptive implants among HIV-positive women in Rwanda. Eur J Contracept Reprod Health Care. 2009;14(6):420-425.

35. Mazia G, Narayanan I, Warren C, et al. Integrating quality postnatal care into PMTCT in Swaziland. Glob Public Health. 2009;4(3):253-270.

36. Warren C, Mwangi A, Oweya E, Kamunya R, Koskei N. Safeguarding maternal and newborn health: improving the quality of postnatal care in Kenya. Int J Qual Health Care. 2010;22(1):24-30.

37. Tawfik Y, Rahimzai M, Ahmadzai M, Clark PA, Kamgang E. Integrating family planning into postpartum care through modern quality improvement: experience from Afghanistan. Glob Health Sci Pract. 2014;2(2):226-233.

38. Vance $\mathrm{G}$, Janowitz $\mathrm{B}$, Chen $\mathrm{M}$, et al. Integrating family planning messages into immunization services: a cluster-randomized trial in Ghana and Zambia. Health Policy Plan. 2014;29(3):359-366.

39. Lee JT, Tsai JL, Tsou TS, Chen MC. Effectiveness of a theory-based postpartum sexual health education program on women's contraceptive use: a randomized controlled trial. Contraception. 2011;84(1):48-56.

40. Akman M, Tüzün S, Uzuner A, Başgul A, Kavak Z. The influence of prenatal counselling on postpartum contraceptive choice. $J$ Int Med Res. 2010;38(4):1243-1249.

41. Sahip Y, Turan JM. Education for expectant fathers in workplaces in Turkey. J Biosoc Sci. 2007;39(6):843-860.

42. Bashour HN, Kharouf MH, Abdulsalam AA, El Asmar K, Tabbaa MA, Cheikha SA. Effect of postnatal home visits on maternal/infant outcomes in Syria: a randomized controlled trial. Public Health Nurs. 2008;25(2):115-125.

43. Alkema L, Kantorova V, Menozzi C, Biddlecom A. National, regional, and global rates and trends in contraceptive prevalence and unmet need for family planning between 1990 and 2015: a systematic and comprehensive analysis. Lancet. 2013;381(9878):1642-1652.

44. Kunene B, Beksinska M, Zondi S, Mthembu N, Mullick S. Involving Men in Maternity Care, South Africa. Durban, South Africa. Washington, DC: USAID; 2004.

45. Warren C, Phafoli S, Majara B, Tsukulu T. Extending Prevention of Mother-to-Child Transmission through Postpartum Family Planning in Lesotho. Washington, DC: USAID; 2008.

46. Ayiasi RM, Muhumuza C, Bukenya J, Orach CG. The effect of prenatal counselling on postpartum family planning use among early postpartum women in Masindi and Kiryandongo Districts, Uganda. Pan Afr Med J $2015 ; 21: 138$.
Open Access Journal of Contraception

\section{Publish your work in this journal}

Open Access Journal of Contraception is an international, peerreviewed, open access, online journal, publishing original research, reports, reviews and commentaries on all areas of contraception. In addition to clinical research, demographics and health-related aspects, the journal welcomes new findings in animal and preclinical studies

\section{Dovepress}

relating to understanding the biological mechanisms and practical development of new contraceptive agents. The manuscript management system is completely online and includes a very quick and fair peer-review system. Visit http://www.dovepress.com/testimonials.php to read real quotes from published authors. 